Usman, Cau Kim Jiu, Wuriani, Kharisma Pratama. Tisa Gusmiah, Yenni Lukita, Jaka Pradika, Gusti Jhoni Putra, Sukarni, Efikasi Diri Dengan Kualitas Hidup Pada Pasien Dengan Luka Kaki Diabetik : Studi Korelasi

\title{
EFIKASI DIRI DENGAN KUALITAS HIDUP PADA PASIEN DENGAN LUKA KAKI DIABETIK : STUDI KORELASI
}

\author{
Usman $^{1}$ \\ STIK Muhammadiyah Pontianak \\ Corresponding author E-mail : usmanudan@stikmuhptk.ac.id \\ Cau Kim Jiu ${ }^{2}$ \\ STIK Muhammadiyah Pontianak \\ Corresponding author E-mail : cki@stikmuhptk.ac.id \\ Wuriani ${ }^{3}$ \\ STIK Muhammadiyah Pontianak \\ Corresponding author E-mail : wuriani@stikmuhptk.ac.id

\section{Kharisma Pratama ${ }^{4}$} \\ STIK Muhammadiyah Pontianak \\ Corresponding author E-mail : kharisma@stikmuhptk.ac.id \\ Tisa Gusmiah ${ }^{5}$ \\ STIK Muhammadiyah Pontianak \\ Corresponding author E-mail : tisa@stikmuhptk.ac.id \\ Yenni Lukita ${ }^{6}$ \\ STIK Muhammadiyah Pontianak \\ Corresponding author E-mail : yenniluk@gmail.com \\ Jaka Pradika ${ }^{7}$ \\ STIK Muhammadiyah Pontianak \\ Corresponding author E-mail : jakapradika@stikmuhptk.ac.id
}

Gusti Jhoni Putra ${ }^{8}$

STIK Muhammadiyah Pontianak

Corresponding author E-mail : gusti16@gmail.com

\section{Sukarni ${ }^{9}$}

Jurusan Keperawatan Fakultas Kedokteran Universitas Tanjungpura

Corresponding author E-mail : sukarni@ners.untan.ac.id

\begin{abstract}
ABSTRAK
Latar Belakang: Angka kejadian diabetes mellitus selalu mengalami peningkatan secara dramatis setiap tahunnya. Salah satu komplikasi yang dapat dialami oleh pasien DM adalah Luka Kaki Diabetik. Angka harapan hidup pasien Luka Kaki Diabetik yang diamputasi adalah 16\%. Berbagai resiko lain yang dapat dialami adalah penurunan kualitas hidup bahkan kematian. Salah satu faktor yang dapat meningkatkan kualitas hidup pasien luka kaki diabetik adalah efikasi diri.

Tujuan: Untuk mengetahui hubungan efikasi diri dengan kualitas hidup pasien dengan Luka Kaki Diabetik.

Metode: Kuantitatif Korelasional dengan pendekatan cross sectional dengan jumlah sampel sebanyak 62 responden. Teknik pengambilan sampel menggunakan consecutive sampling. Intstrumen yang digunakan adalah kuesioner efikasi diri dan kualitas hidup. Analisis yang digunakan adalah uji chi-square.

Hasil: Hasil peneltian menunjukkan bahwa jumlah penderita pasien Luka Kaki Diabetik lebih banyak dialami oleh perempuan dan berusia sekitar 45-59 tahun. 51\% pasien Luka Kaki Diabetik memiliki efikasi diri yang baik dan $54 \%$ memiliki kualitas hidup yang baik. Ada hubungan secara statistic antara efikasi diri dengan kualitas hidup pasien dengan luka kaki diabetik dengan $p$ value 0.002 .
\end{abstract}


Usman, Cau Kim Jiu, Wuriani, Kharisma Pratama. Tisa Gusmiah, Yenni Lukita, Jaka Pradika, Gusti Jhoni Putra, Sukarni, Efikasi Diri Dengan Kualitas Hidup Pada Pasien Dengan Luka Kaki Diabetik : Studi Korelasi

Kesimpulan : semakin baik efikasi diri maka semakin baik juga kualitas hidup pasien dengan luka kaki diabetik

Kata Kunci : Efikasi Diri, Kualitas Hidup, Luka Kaki Diabetik

\section{ABSTRACT}

The incidence of diabetes mellitus has always increased dramatically every year. One of the complications that can be experienced by DM patients is Diabetic Foot Ulcer. The life expectancy of patients with amputated Diabetic Foot Ulcer is $16 \%$. Various other risks that can be experienced are decreased quality of life and even death. One of the factors that can improve the quality of life of diabetic foot ulcer patients is self-efficacy. The aim of this study was to determine the relationship between self-efficacy and quality of life of patients with diabetic foot ulcer. This research method is quantitative with cross sectional approach with a total sample of 62 respondents. The sampling technique used consecutive sampling. The instrument used was a self-efficacy and quality of life questionnaire. The anlysis was used chi-square. The results showed that the number of patients with Diabetic Foot ulcer was more experienced by women aged around $45-59$ years. $51 \%$ of patients with Diabetic Foot ulcer had good self-efficacy and $54 \%$ had a good quality of life. There is a statistical relationship between self-efficacy and quality of life of patients with diabetic foot ulcer with $p$ value 0.002. Conclusion: the better the self-efficacy, the better the quality of life for patients with diabetic foot ulcer will be.

Keywords : Self-Efficacy, Quality of Life, Diabetic Foot Ulcer

\section{PENDAHULUAN}

Ketika tubuh tidak dapat memproduksi insulin secara cukup, maka jumlah glukosa didalam pembuluh darah sangat tinggi yang disebut Diabetes Mellitus (IDF, 2015). Penyakit Diabetes Mellitus ini merupakan salah satu penyakit kronis yang dialami oleh penderita didunia yang mana angka kejadiannya selalu mengalami peningkatan secara dramatis setiap tahunnya (Artanti, dkk, 2015). Seseorang yang mengalami DM ini akan memiliki beberapa tantangan hidup seperti terapi farmakologis secara terus menerus, pembatasan diet dan kontrol gula darah puasa secara berkala (Retnowati \& Prijono, 2015).

Berbagai komplikasi akan bermunculan pada penderita DM apabila tidak ditangani dengan baik (Laoh \& Debora, 2015; Rahman dkk, 2017). Salah satu komplikasi yang akan dialami oleh pasien DM adalah Luka Kaki Diabetik (LKD) (Meidikayanti \& Chatarina, 2017). Sebanyak $25 \%$ penderita LKD akan mengalami kecacatan dan $16 \%$ akan mengalami kematian. Berbagai komplikasi tersebut juga akan mengalami penurunan kualitas hidup yang dapat dibuktikan dengan usia harapan hidup sebesar 5-10 tahun (Herdianti, 2017; Sari, 2017).

Kualitas hidup adalah persepsi seseorang dalam konteks budaya dan sistem yang sesuai dengan tempat hidup orang tersebut serta berkaitan dengan tujuan, harapan, standar dan fokus atau kepedulian selama hidupnya (Retnowati \& Prijono, 2015). Berbagai factor yang mempengaruhi kualtas hidup pasien LKD adalah usia, jenis kelamin, Pendidikan, status pernikahan dan lama menderita serta efikasi diri yang baik (Weiner \& Neugehauer, 2013; Spasic dkk, 2014; Faridah \& Venty, 2016 ; Hatmanti, 2017; Nuraisyah dkk, 2017). Efkasi diri adalah keyakinan individu akan kemampuannya untuk mengatur dan melakukan tugas tertentu berfokus pada perubahan perilaku penderita guna mendapatkan hasil yang diharapkan (AlKahfi dkk, 2016; Hatmanti, 2017). Dari uraian diatas, maka peneliti tertarik untuk meneliti tentang hubungan efikasi diri dengan kualitas hidup pasien Luka Kaki Diabetik. Tujuan penelitian ini adalah untuk mengetahui hubungan antara efikasi diri dengan kualitas hidup pasien dengan Luka kaki Diabetik. 


\section{METODE PENELITIAN}

Penelitian ini merupakan penelitian kuantitaif dengan pendekatan crossectional. Jumlah sampel yang digunakan 62 orang dengan penderita Luka Kaki Diabetik. Teknik pemilihan sampel menggunakan consecutive sapling yaitu pemilihan sampel dengan menetapkan subyek yang memenuhi kriteria penelitian sampai kurun waktu tertentu sehingga jumlah responden yang diperlukan terpenuhi yang dilakukan dari Januari sampai Juni 2019. Instrumen penelitian ini menggunakan DMSES dan DQOL dengan nilai validitas DMSES adalah 0.362 , alpha Cronbach 0.80 . sedangkan DQOL memiliki nilai uji validitas 0.428 dan alpha Cronbach 0.93 sehingga kedua instrument ini dapat dinyatakan valid dan reliabel. analisis yang digunakan adalah uji chi square.

\section{HASIL DAN PEMBAHASAN}

Tabel 1. distribusi frekuensi berdasarkan usia, jenis kelamin, pekerjaan dan Pendidikan.

\begin{tabular}{|c|c|c|}
\hline \multicolumn{3}{|c|}{ Karakteristik reponden } \\
\hline \multicolumn{3}{|c|}{ Usia } \\
\hline 45-59 tahun & 41 & 66.1 \\
\hline 60-74 tahun & 17 & 27.4 \\
\hline 75-90 Tahun & 4 & 6.5 \\
\hline Total & 62 & 100 \\
\hline \multicolumn{3}{|l|}{ Jenis Kelamin } \\
\hline Laki-laki & 15 & 24.2 \\
\hline Perempuan & 47 & 75.8 \\
\hline Total & 62 & 100 \\
\hline \multicolumn{3}{|c|}{ Tingkat Pendidikan } \\
\hline SD Sederajat & 18 & 29.0 \\
\hline SMP Sederajat & 14 & 22.5 \\
\hline SMA Sederajat & 28 & 45.1 \\
\hline Perguruan Tinggi & 4 & 6.4 \\
\hline Total & 62 & 100 \\
\hline \multicolumn{3}{|l|}{ Pekerjaan } \\
\hline Pedagang & 7 & 11.4 \\
\hline PNS & 9 & 14.8 \\
\hline Ibu Rumah Tangga & 31 & 50.0 \\
\hline Lainnya & 14 & 23.8 \\
\hline Total & 62 & 100 \\
\hline
\end{tabular}

Sumber :Data primer telah diolah tahun 2019

Tabel diatas menggambarkan bahwa berdasarkan usia, mayoritas berada pada rentang 45-59 tahun sebanyak $66.1 \%$, berdasarkan jenis kelamin mayoritas responden adalah berjenis kelamin prempuan sebanyak $75.8 \%$, berdasarkan Pendidikan mayoritas responden berpendidikan tamatan SMA/ sederajat sebesar $45.1 \%$, berdasarkan pekerjaan ayoritas responden adalah lbu Rumah Tangga sebesar $50 \%$.

Utami pada tahun 2014 mengatakan bahwa Usia mempengaruhi tingkat penuaan sehingga sistem integumen dan sirkulasi juga megalami fungsi secara terus menurun. Semakin bertambah usia seseorang akan semakin beresiko mengalami DM dan berujung kepada Luka Kaki Diabetik. Hal senada juga disampaikan IDF pada tahun 2013 mengatakan bahwa usia 40-59 tahun adalah usia yang sangat beresiko seseorang mengalami DM bahkan Luka Kaki Diabetik.

Selain itu usia yang tua juga akan mempengaruhi efikasi diri yang berdampak pada kualitas hidup pada pasien Luka Kaki Diabetik. Berdasarkan frekuensi jenis kelamin, perempuan lebih beresiko mengalami DM adalah perbedaan kadar hormone seksual antara perempuan dan laki-laki dewasa. Jaringan adiposa pada perempuan lebih banyak daripada perempuan diabandingkan laki-laki , dimana perempuan memiliki 20-25 \% sedangkan laki-laki hanya $15-20 \%$ dari berat badan ( Prasetyani, 2017).

Berdasarkan Pendidikan Menurut Ningsih (2018) bahwa dengan tingginya tingkat pendidikan seseorang maka akan semakin mudah pula seseorang dalam mendapatkan dan memahami suatu informasi, hal ini akan membantu seseorang agar bisa memahami keadaan yang berhubungan dengan sakitnya serta melakukan perawatan diri. berbeda dengan penelitian Wahyuni (2014) menyatakan bahwa persentase kualitas hidup tinggi terbesar berada pada tingkat pendidikan perguruan tinggi yakni sebanyak $78,26 \%$.

Tingginya kualitas hidup pada seseorang yang berpendidikan tinggi dikarenakan mereka cenderung mencari tahu lebih banyak mengenai penyakit mereka dari berbagai media informasi. Pengetahuan yang baik memungkinkan pasien DM dengan 
pendidikan tinggi akan lebih mengenali tentang penyakit mereka.

Status pekerjaan berhubungan dengan aktualisasi diri individu dan mendorong individu untuk lebih percaya diri dan bertanggung jawab dalam menyelesaikan tugas. Namun, individu yang bekerja kemungkinan besar mempunyai kegiatan yang padat dan beresiko mengalami stress yang tinggi pada pekerjaannya sehingga dapat mempengaruhi efikasi dirinya dalam memanajemen penyakitnya. Pasien DM yang tidak bekerja memiliki waktu yang lebih banyak untuk mengelola penyakitnya termasuk melakukan perawatan kaki diabetes (Ariani, 2012).

Tabel 2 Hubungan Efikasi Diri dengan Kualitas Hidup

\begin{tabular}{l|ccccc}
\multicolumn{5}{c}{ Variabel } & \multicolumn{5}{c}{ Kualitas Hidup } \\
\hline Efikasi & Baik & $\%$ & Kurang & $\%$ \\
Diri & & & & & 0.002 \\
Baik & 25 & 40.3 & 7 & 11.3 & \\
Kurang & 11 & 17.8 & 19 & 30.6 & \\
\hline
\end{tabular}

Sumber : data primer telah diolah tahun 2019

Berdasarkan tabel diatas dapat disimpulkan bahwa ada hubungan antara efikasi diri dengan kualitas hidup pasien dengan Luka Kaki Diabetik dengan nilai $p$. value 0.002 .

Hasil penelitian ini sejalan dengan penelitian yang dilakukan oleh Retnowati \& Prijono (2015) yaitu terdapat hubungan efikasi diri dengan kualitas hidup penderita Luka Kaki Diabetik. Salah satu faktor yang dapat meningkatkan kualitas hidup seseorang adalah efikasi diri yang baik.

Sebuah Efikasi diri tersebut mengacu pada keyakinan individu tentang kemampuannya untuk menghasilkan perilaku yang ingin dicapai dan tentunya akan berpengaruh pada kehidupan individu tersebut. Efikasi diri tersebut akan menentukan seseorang dalam merasa, berfikir, memotivasi dirinya dan bertindak (Tsang, 2012). Efikasi diri yang kuat akan menetapkan tujuan seseorang untuk melakukan perilaku kesehatan serta pengelolaan perawatan diri terkait penyakitnya (Kusuma \& Wahyu, 2013).

Seseorang yang mengalami Luka Kaki Diabetik dengan efikasi diri yang baik cenderung memiliki rasa khawatir yang rendah dalam mengerjakan sebuah tanggung jawab. Hal tersebut disebabkan oleh mereka mempunyai kontrol yang baik pula terhadap segala sesuatu yang akan dikerjakannya (Damayanti, 2017). Selain itu menurut Hatmanti tahun 2017 adanya efikasi diri yang baik akan mendorong seseorang dalam melakukan tindakan untuk mencapai kesuksesan sehingga kualitas hidup pasien dengan Luka Kaki akan mengalami peningkatan.

Sedangkan, pada penderita Luka Kaki Diabetik dengan efikasi diri yang kurang, mereka cenderung tidak pernah mencoba untuk melakukan sesuatu yang mereka yakini bermanfaat bagi dirinya. Adanya perasaan tidak bisa untuk melakukan perubahan tersebut membuat mereka takut mencoba sesuatu. Hal inilah yang mengakibatkan pada penderita Luka Kaki Diabetik dengan efikasi diri yang kurang cenderung mengalami penurunan kualitas hidup (Afrida, 2017).

\section{KESIMPULAN}

Pederita Luka Kaki Diabetik paling banyak diderita oleh perempuan degan rentan usia 45-59 tahun. Selain itu Semakin baik efikasi diri maka akan semakin baik kualitas hidup pasien dengan Luka Kaki Diabetik.

\section{SARAN}

Perlu dilakukan penelitian dengan tema factor-faktor yang dapat mempengaruhi efikasi diri pasien Luka kaki Diabetik maupun berbagai intervensi yang dapat meningkatkan efikasi diri pasien dengan Luka Kaki Diabetik.

\section{DAFTAR PUSTAKA}

Afrida, 2017. Hubungan Efikasi Diri Dengan Kualitas Hidup Pada Pasien Diabetes Melitus Tipe II Di Rumah Sakit Labuang Baji Makassar. Jurnal IImiah Kesehatan Diagnosis, 10(6), 595-599. 
Usman, Cau Kim Jiu, Wuriani, Kharisma Pratama. Tisa Gusmiah, Yenni Lukita, Jaka Pradika, Gusti Jhoni Putra, Sukarni, Efikasi Diri Dengan Kualitas Hidup Pada Pasien Dengan Luka Kaki Diabetik: Studi Korelasi

Al-Kahfi, R., Adriana P., \& Marlina. (2016). Pengaruh Efikasi Diri Dan Dukungan Keluarga Terhadap Pencegahan Kaki Diabetik Pada Pasien Rawat Jalan Diabetes Mellitus Tipe 2 Di RSUD dr. H. Moch. Ansari Saleh Banjarmasin. DinamikaKesehatan, 7(2), 332-346.

Ariani, Y., Ratna S., \& Dewi G. (2012). Motivasi Dan Efikasi Diri Pasien Diabetes Melitus Tipe 2 Dalam Auhan Keperawatan. Jurnal Keperawatan Indonesia, 15(1), 29-38.

Damayanti, S. (2017). Efektivitas SelfEfficacy Enhancement Intervention Program (SEEIP) Terhadap Efikasi Diri Manajemen Diabetes Mellitus Tipe 2. Jurnal Keperawatan Respati Yogyakarta, 4(2), 148-153.

Faridah, I. N. \& Venty D. (2016). Hubungan Usia Dan Penyakit Penyerta Terhadap Kualitas Hidup Pasien Diabetes Melitus Tipe 2 Di Puskesmas Kotaagede 1 Yogyakarta. Prosiding Rakernas dan Pertemuan IImiah Tahunan Ikatan Apoteker Indonesia 2016, 123-126.

Hatmanti, N. M. (2017). Hubungan Antara Self Efficacy Dengan Qualitt Of Life Pada Pasien Diabetes Melitus Tipe 2 Di Wilayah Kerja Puskesmas Kebonsari Surabaya. Jurnal IImiah Kesehatan, 10(2), 241-249.

Herdianti. (2017). Determinan Kualitas Hidup Penderita Dm Tipe 2 Di Rsud Ajjappange. Journal Endurance, 2(1), 7480.

International Diabetes Federation. (2013). IDF Diabetes Atlas Seventh Edition 2015. Diunduh 15 Februari 2018, dari diabetesatlas.org/resources

Internatonal Diabetes Federation (2015). IDF Diabetes Atlas Eighth Edition 2017. Diunduh 15 Februari 2018, dari www.diabetesatlas.org

Monitoring sebagai Variabel Mediasi. ElQudwah,. 04(2008) 1-19.

Kusuma, H., \& Wahyu H. (2013). Hubungan Antara Motivasi Dengan Efikasi Diri Pada Pasien Diabetes Mellitus Tipe 2 Di
Persadia Salatiga. Jurnal Keperawatan Medikal Bedah, 1(2), 132-141.

Laoh, J. M., \& Debora T. (2015). Gambaran Kualitas Hidup Pasien Diabetes Mellitus Di Poliklinik Endokrin RSUP PROF. Dr. R. D. Kandou Manado. Juiperdo, 4(1), 32-37.

Larasati, TA. (2012). Kualitas Hidup Pasien Diabetes Melitus Tipe 2 Di RS Abdul Moeloek Propinsi Lampung. Jurnal Kedokteran dan Kesehatan Universitas Lampung, 2(2), 17-20.

Meidikayanti, W., \& Chatarina U. W. (2017). Hubungan Dukungan Keluarga Dengan Kualitas Hidup Diabetes Melitus Tipe 2 Di Puskesmas Pademawu. Jurnal Berkala Eoidemiologi, 5(2), 240-252.

Ningsih, H. R., Bayhakki, \& Rismadefi W. (2018). Hubungan Self Efficacy Terhadap Kepatuhan Diit Pada Penderita DM. Jurnal Online Mahasiswa, Vol 5, 212219.

Retnowati, N. \& Prijono S. (2015). Hubungan Dukungan Keluarga Dengan Kualitas Hidup Penderita Diabetes Melitus Di Puskesmas Tanah Kalikedinding. Jurnal Berkala Epidemiologi, 3(1), 57-68.

Sari, L. S. (2017). Analisis Biaya Akibat Sakit serta Kualitas Hidup Pasien Diabetes Mellitus Tipe 2 dengan Penyakit Jantung. Jurnal Ekonomi Kesehatan Indonesia, 1(3), 126-131.

Tsang, S. KM. (2012). Self-Efficacy as a Positive Youth Development Construct A Conceptual Review. The Scientific Word Journal, Vol 2012, 1-7.

Wahyuni Y., Nursiswati., \& Anastasia A. (2014). Kualitas Hidup berdasarkan Karekteristik Pasien Diabetes Melitus Tipe 2. Jurnal Keperawatan Padjadjaran, 2(1), 25-34.

Weiner, S., \& Neugehauer. (2013). Quality of Life of Diabeteic Patients With Medical or Surgical Treatment. Nutricion Hospitalaria. 28(2). 66-77. 